\title{
Características discursivas de um episódio de estágio de docência em acordo com os PCNs: um exemplo a partir da diferenciação entre massa e peso
}

\author{
Discursive characteristics of an episode of supervised \\ teaching with respect to the PCNs: \\ an example of differentiation between mass and weight
}

Rodrigo Drumond Vieira

Silvania Sousa do Nascimento

Carlos Eduardo Porto Villani

\begin{abstract}
Resumo
Neste trabalho buscamos compreender algumas características discursivas de uma prática docente em acordo com as diretrizes dos PCNs do Ensino Médio e focalizamos em licenciandos em Física, freqüentes na disciplina Prática de Ensino de Física, na qual é realizado o estágio curricular de docência. Primeiramente, buscamos sondar indiretamente as concepções pedagógicas de ciência dos licenciandos de maneira a verificar a sua compatibilidade com as diretrizes dos PCNs. Numa segunda etapa, selecionamos, dentre o grupo sondado, um licenciando cuja concepção pedagógica de ciência se mostrou mais compatível com tais diretrizes. Em seguida, a partir da transcrição de uma aula regida pelo licenciando selecionado, realizamos uma análise discursiva através de uma estrutura de análise de interações discursivas. Por fim, sugerimos que as análises discursivas de práticas docentes em acordo com os PCNs podem contribuir para o estabelecimento de um conhecimento de referência para licenciandos e professores de ciências, em particular, licenciandos e professores de física.
\end{abstract}

Palavras-chave: PCNs; concepções pedagógicas de ciência; interações discursivas.

\section{Abstract}

In this present study we try to comprehend some discursive characteristics of an teaching practice in accord with the high school PCNs guidelines and we focus on students physics teachers, who are frequent in the subject Practice of Physics 
Teaching II, which the teaching traineeship takes place. Firstly, we indirectly try to explore the pedagogical conceptions of science from the teaching traineeship, in order to verify their compatibility with the PCNs guidelines. In a second stage, we selected, in the explored group, one student whose pedagogical conception of science had shown more compatible with those guidelines. Next, from the transcription of a class given by the selected one, we executed a discursive analysis through an analysis structure of discursive interactions. At last, we suggest that the discursive analysis of teaching practices in accord with the PCNs might contribute to the settlement of a knowledge of reference to science teachers, in particular, physics students and teachers..

Keywords: PCNs; pedagogical conceptions of science; discursive Interactions.

\section{Introdução}

Os PCNs do Ensino Médio (Parâmetros Curriculares Nacionais do Ensino Médio, MECSEMTEC, 2002), na categoria de discurso, é um texto prescritivo atual e nacional de referência para o Ensino Médio. Ele nos aponta um ponto de partida para a elaboração, por parte dos professores, dos fazeres didáticos frente ao contexto de globalização no qual o Brasil se insere (OLIVEIRA, 2005).

Estamos imersos na era da informação, e a tendência deste momento histórico aponta para novas necessidades de formação dos sujeitos, enquanto cidadãos e pessoas autônomas. Os PCNs incorporam tais necessidades quando prescrevem a formação de cidadãos críticos, preparados para o processo democrático (RIBEIRO et al, 2005), capazes de relacionar as diversas áreas do conhecimento e de formular respostas aos vários problemas que se impõem na vida de maneira articulada e coerente. A capacidade de pesquisa e a capacidade de aprender a aprender é uma competência por eles valorizada, conforme pode ser inferido do seguinte trecho:

Propõe-se, no nível do Ensino Médio, a formação geral, em oposição à formação específica; o desenvolvimento das capacidades de pesquisar, buscar informações, analisá-las e selecioná-las; a capacidade de aprender, criar, formular, ao invés do simples exercício de memorização. (PCNs do Ensino Médio, MEC-SEMTEC, 2002, p. 16, grifos nossos)

Balizando em sua constituição para esse horizonte, os PCNs se constituem um texto oficial que orienta a nova e desejada postura profissional dos professores. Apesar das críticas às dificuldades de transposição para a sala de aula de suas recomendações, especialmente em virtude de constituírem uma tentativa de currículo nacional (cf. LOPES, 2004; FRIGOTTO \& CIAVATTA, 2003), a expectativa geral é a consolidação de uma prática que resulte em uma formação mais ampla dos alunos no que diz respeito à interdisciplinaridade e aquisição de 
habilidades e competências. A definição das habilidades e competências busca evidenciar os aspectos caros e necessários aos sujeitos como meios pelos quais eles poderão exercer a sua cidadania.

Situando-se esta discussão no quadro mais amplo da epistemologia sócio-discursiva (cf. VYGOTSKY, 1978; BAKHTIN, 2000; BRONCKART, 1999), os aspectos discursivos em sala de aula passam a ser reconhecidos como fundamentais para a construção e compartilhamentos de conhecimentos. Candela (1999), por exemplo, considera que diferentes formas de manifestações discursivas podem levar a diferentes conceitualizações pelos alunos acerca de um mesmo fenômeno ou conteúdo curricular.

Assim, consideramos as práticas discursivas em sala de aula como fundamentais para o desenvolvimento dos processos de ensino e aprendizagem. Deste modo, torna-se imperativo construir um conhecimento sobre as características discursivas de uma prática docente que esteja em acordo com as diretrizes dos PCNs, pois uma investigação dessa natureza permitiria aperfeiçoamentos e críticas, além de servir como possibilidade de referência para professores em situações concretas de sala de aula (cf. VIEIRA, 2007; VIEIRA \& NASCIMENTO, 2007).

Apesar da importância da compreensão das práticas discursivas em sala de aula, o conhecimento de suas características na formação inicial de professores de ciências pode ser considerado ainda bastante lacunar (MUNFORD, et. al., 2005; ANDRÉ, 2002), especialmente as práticas discursivas de licenciandos em situações de estágio curricular de docência.

Portanto, o objetivo deste artigo é justamente caracterizar alguns elementos do discurso produzido em uma aula de estágio curricular de regência, e enquanto um primeiro ensaio, estudamos um licenciando cuja prática docente esteve de acordo com algumas das diretrizes dos PCNs. Isso nos levou, primeiramente, à necessidade de selecionar um licenciando cujas orientações pedagógicas satisfaçam a exigência de compatibilidade com aquelas dos PCNs.

Assim, num primeiro momento, buscamos sondar o que chamamos de "concepções pedagógicas de ciência", que são as concepções que os licenciandos têm a respeito de como o conteúdo científico deve ou deveria ser ensinado aos seus alunos. Delineada dessa forma a nossa interpretação do termo, avaliamos que poderá haver uma conexão entre as concepções pedagógicas de ciência e o tipo de abordagem que o professor de ciências terá ao ministrar suas aulas no Ensino Médio, o que poderá favorecer ou não a formação dos seus alunos segundo as diretrizes dos PCNs. Apesar de estudos (cf. LEDERMAN, 1999; MELLADO, 1997) indicarem que as concepções de Natureza da Ciência dos professores não necessariamente interferem nas suas práticas, julgamos que esse não é o caso para as concepções pedagógicas de ciência, pois elas mantêm uma relação de proximidade com os propósitos do professor/licenciando, sendo tais propósitos um fator determinante da prática docente (LEDERMAN, 1999). 
Neste ensaio, enquanto um componente de uma pesquisa concluída sobre a formação inicial dos professores de física, buscamos caracterizar as concepções pedagógicas de ciência de um grupo de licenciandos como aquelas em acordo ou desacordo com as diretrizes dos PCNs, e as utilizamos como um indicador de afinidade entre os PCNs e a prática de estágio docente. Mais especificamente, ao sondarmos as concepções pedagógicas de ciência, fizemo-lo indiretamente através de um questionário que de maneira clara remete às concepções de natureza da ciência e as dicotomiza como construtivista e não-construtivista. Assim procedemos por entendermos que, ao sondarmos uma concepção de natureza da ciência com tendências construtivistas, podemos, por hipótese, transpor as suas pressuposições epistemológicas científicas para uma concepção pedagógica de ciência construtivista correspondente, logo, em concordância com as diretrizes dos PCNs.

Justificamos nossa opção em utilizar um instrumento de acesso indireto às concepções pedagógicas de ciência pelo nosso julgamento de que uma tentativa de identificar diretamente tais concepções resultaria em dados tendenciosos, visto a prévia e recente exposição dos licenciandos pesquisados a temas subjacentes a um ensino contextualizado e ligado ao cotidiano dos alunos. Por isso, optamos por um acesso indireto às concepções pedagógicas de ciência, mas que, pelo seu caráter indireto, esperaríamos que evitasse o referido possível caráter tendencioso que poderia advir do uso de um instrumento de acesso direto.

Para sondarmos a compatibilidade das concepções dos licenciandos com a dimensão construtivista da Natureza da Ciência (e, indiretamente, com as concepções pedagógicas de ciência em concordância com os PCNs) aplicamos 05 questões abertas (veja o ANEXO I) ao grupo de licenciandos freqüentes na disciplina de Prática de Ensino de Física II, do último período do curso de Licenciatura e realizando o estágio curricular de docência. Todos os licenciandos sondados pertenciam a mesma turma (a disciplina era ministrada a duas turmas) e a sondagem foi realizada no segundo semestre de 2004. Nossa seleção dos sujeitos nessa etapa de formação se justifica na consideração de que as concepções pedagógicas de ciência, muitas vezes, se refinam no momento de preparação das seqüências de ensino para o estágio curricular obrigatório. Além disso, devíamos satisfazer o objetivo de pesquisa de analisar a prática docente discursiva de um licenciando, e a única etapa no curso de formação dos licenciandos que atende oficialmente essa exigência, no contexto de realização da nossa pesquisa, é a disciplina Prática de Ensino de Física II.

O questionário, por sua vez, é de um caráter restrito no sentido de apontar somente dicotomicamente concepções de Natureza da Ciência: aquela construtivista a aquela nãoconstrutivista. A partir dessa classificação, relacionamos, de forma simplificada neste estudo, a tendência epistemológica construtivista com uma concepção pedagógica de ciência em acordo 
com os PCNs, e aquela tendência epistemológica não construtivista com uma concepção pedagógica de ciência em desacordo com as diretrizes dos PCNs, conforme descrito a seguir.

Concepção de Natureza da Ciência construtivista: considera que o conhecimento científico submete-se a um processo de produção cuja dinâmica envolve transformações na compreensão do comportamento da natureza que impedem esse conhecimento de ser caracterizado como pronto, verdadeiro e acabado, mesmo que as teorias produzidas constituam verdades históricas que têm fundamentado o homem de ciência para uma explicação dos fenômenos (DELIZOICOV, ANGOTTI, PERNAMBUCO, 2002). Essa concepção de Natureza da Ciência pode ser relacionada a uma concepção pedagógica da ciência compatível com os PCNs devido a sua formulação (contextualização e mutabilidade de leis e teorias), a qual pode ser transposta para uma concepcão da aprendizagem dos alunos como uma (re)construção de conhecimentos a partir de seus conceitos iniciais, que poderão ver-se modificados - como ocorre com os próprios cientistas, - ao longo da pesquisa (GIL-PÉREZ, 2001). Assim, avaliamos que essa concepção pedagógica de ciência colabora para uma prática docente na qual a (re)construção do conhecimento é um aspecto presente e constante.

Concepção de Natureza da Ciência não-construtivista: Devido a sua formulação (rigidez de conceitos, descontextualização e imutabilidade das teorias), associamos esta concepção de Natureza da Ciência com uma concepção pedagógica de ciência em desacordo com os PCNs, a qual trata da Física como conteúdo disciplinar embasado na mera transmissão de conhecimentos prontos, tidos como verdadeiros e irrefutáveis. Deste modo, avaliamos que essa concepção pedagógica de ciência colabora para uma prática docente que privilegia bastante a postura repetitiva de leis e equações e o conseqüente distanciamento dos modos de desenvolvimento e construção do conhecimento científico e suas vinculações históricas, contribuindo para uma transmissão unidirecional de um conhecimento pronto e acabado do professor para o aluno.

Portanto, não pretendemos apontar com o questionário a diversidade de concepções de Natureza da Ciência, mas sim, separá-las segundo o seu teor epistemológico construtivista, por meio do qual pudemos enquadrá-las em uma ou noutra das duas categorias de concepções pedagógicas de ciência, fundamentando para isso os nossos critérios nos PCNs.

Destacamos, nos trechos seguintes, a orientação construtivista dos PCNs que vai contra a dimensão tradicional do ensino:

[O ensino de física] freqüentemente apresenta o conhecimento como produto acabado, fruto de genialidade de mentes como Galileu, Newton ou Einstein, contribuindo para que os alunos concluam que não resta mais nenhum problema significativo a resolver. Além disso, envolve uma lista de conteúdos demasiadamente extensa, que impede o aprofundamento 
necessário e a instauração de um diálogo construtivo (PCNs, 2002, p. 229 e 230).

Esta proposta de condução do aprendizado [construtivismo] tem sido aperfeiçoada no sentido de se levar em conta que a construção do conhecimento científico envolve valores humanos, relaciona-se com a tecnologia e, mais geral, com toda a vida em sociedade, de se enfatizar a organicidade conceitual das teorias científicas, de se explicitar a função essencial do diálogo e da interação social na produção coletiva. Tais redirecionamentos têm sido relevantes para a educação científica $e$ matemática e, certamente, suas idéias influenciam o presente esforço de revisão de conteúdos e métodos para a educação científica (PCNs do Ensino Médio, MEC-SEMTEC, 2002, p. 262).

Após a sondagem, selecionamos um licenciando cuja pontuação do questionário fosse aquela que indicasse uma concepção pedagógica de ciência em grande acordo com os PCNs (ou seja, uma pontuação mais positiva). A partir da transcrição de uma aula ministrada pelo licenciando selecionado, durante o seu estágio curricular de regência, buscamos caracterizar o discurso nela produzido, o qual, se avaliado contrário às diretrizes dos PCNs, motivaria a seleção de outro licenciando a partir dos resultados do questionário, até que a exigência de acesso a uma prática discursiva em acordo com os PCNs fosse satisfeita.

Tendo em vista as nossas considerações sobre concepção pedagógica de ciência e prática docente e, levando em conta que as situações discursivas são parte inerente e fundamental da prática docente, utilizamos a estrutura de análise discursiva proposta por Mortimer \& Scott (2003) para investigar, na aula transcrita, as interações discursivas de ensino e aprendizagem de ciências, especialmente considerando as contribuições discursivas do licenciando que ministrou a aula. Com isso, foi possível caracterizar o discurso e estratégias do licenciando selecionado e avaliar neles indicadores que remetem à sua compatibilidade com as diretrizes estabelecidas pelos PCNs.

\section{Métodos para a análise da sala de aula}

Considerando o objetivo ora exposto, a análise dos dados foi realizada a partir da estrutura analítica proposta por Mortimer e Scott (2003), sendo que, a partir dessa estrutura, a inter-relação entre os "propósitos do professor", "abordagem comunicativa" e "padrões de discurso" foi levada em conta no sentido de evidenciar possíveis relações entre as diretrizes dos PCNs e o discurso gerenciado em sala de aula pelo licenciando selecionado. 


\section{A estrutura de análise proposta por Mortimer e Scott (2003)}

A estrutura analítica proposta baseia-se na teoria sociocultural de Vygotsky (1978). De acordo com esse autor, o desenvolvimento e o aprendizado envolvem uma passagem do contexto social para o contexto individual através da internalização, sendo que a linguagem é considerada um fator determinante desse processo. Fundamentando a sua estrutura analítica nesse marco teórico, Mortimer e Scott (2003) apontam cinco aspectos interligados, os quais focalizam na função do professor em tornar os conceitos científicos disponíveis no plano social de sala de aula e dar suporte aos estudantes de construírem sentido sobre esses conceitos. Os cinco aspectos foram agrupados como mostra a Tabela 1.

Tabela 1: Os aspectos da análise

\begin{tabular}{|l|l|l|}
\hline Focalização & 1. Propósitos & 2. Conteúdos \\
\hline Abordagem & \multicolumn{2}{|c|}{ 3. Abordagem comunicativa } \\
\hline Ação & 4. Padrões de discurso & 5. Intervenções do professor \\
\hline
\end{tabular}

Fonte: Mortimer e Scott (2003); pág 25 (tradução nossa).

No contexto desse estudo, vamos nos concentrar apenas "nos propósitos do professor", "na abordagem comunicativa" e "nos padrões de discurso". Nossa intenção é avaliar nesses três aspectos se existem indícios discursivos na aula transcrita que estejam relacionados a algumas das recomendações dos PCNs que expusemos anteriormente. A seguir indicamos um breve e resumido panorama acerca dos três referidos aspectos.

\section{Propósitos do professor}

A Tabela 2 resume os propósitos a serem atingidos e a respectiva focalização quando do engajamento nesses propósitos:

Tabela 2:- Propósitos do professor

\begin{tabular}{|l|l|}
\hline Propósito do professor & Como focalizar o propósito \\
\hline Abertura de um problema & $\begin{array}{l}\text { Engajando os estudantes intelectualmente e } \\
\text { emocionalmente no desenvolvimento inicial dos } \\
\text { conceitos científicos. }\end{array}$ \\
\hline $\begin{array}{l}\text { Explorar e trabalhar os pontos de vista dos } \\
\text { estudantes. }\end{array}$ & $\begin{array}{l}\text { Sondando os pontos de vista dos estudantes e suas } \\
\text { interpretações de idéias específicas e de } \\
\text { fenômenos. }\end{array}$ \\
\hline
\end{tabular}




\begin{tabular}{|l|l|}
\hline Introduzir e desenvolver os conceitos científicos. & $\begin{array}{l}\text { Tornando os significados científicos disponíveis no } \\
\text { plano social da sala de aula. }\end{array}$ \\
\hline $\begin{array}{l}\text { Guiar os alunos a trabalhar com os significados } \\
\text { científicos e dar suporte a internalização. }\end{array}$ & $\begin{array}{l}\text { Providenciando oportunidades para os alunos } \\
\text { falarem e pensarem com os novos significados } \\
\text { científicos, individualmente ou em grupos. }\end{array}$ \\
\hline $\begin{array}{l}\text { Guiar os alunos a aplicar e expandir o uso do ponto } \\
\text { de vista científico e adquirir responsabilidade por } \\
\text { esse uso. }\end{array}$ & $\begin{array}{l}\text { Dando suporte aos estudantes na aplicação dos } \\
\text { significados científicos ensinados em uma gama de } \\
\text { contextos diferentes ou inter-relacionados. }\end{array}$ \\
\hline $\begin{array}{l}\text { Manutenção do desenvolvimento da construção de } \\
\text { conceitos científicos. }\end{array}$ & $\begin{array}{l}\text { Providenciando comentários acerca dos conceitos } \\
\text { científicos ainda não desenvolvidos e ajudando os } \\
\text { alunos a seguir o seu desenvolvimento. }\end{array}$ \\
\hline
\end{tabular}

\section{Abordagem Comunicativa}

Esse conceito é central à estrutura, por providenciar uma perspectiva de como o professor trabalha com os estudantes ao desenvolver idéias em sala de aula. Esse aspecto da estrutura indica o tipo de interação do professor com o aluno, e como ela pode ser classificada.

Os autores identificaram quatro classes fundamentais de abordagem comunicativa, que podem ser definidas pela caracterização da fala entre professor e alunos ao longo de duas dimensões: dialógica - de autoridade e interativa - não-interativa. A Tabela 3 ilustra as combinações dessas dimensões.

Tabela 3: Quatro classes da abordagem comunicativa

\begin{tabular}{|l|l|l|}
\cline { 2 - 3 } \multicolumn{1}{l|}{} & INTERATIVA & NÃO-INTERATIVA \\
\hline DIALÓGICA & A. Interativa/dialógica & B. Não-interativa/dialógica \\
\hline DE AUTORIDADE & C. Interativa/de autoridade & D. Não-interativa/de autoridade \\
\hline
\end{tabular}

Essas classes são definidas pelos autores da seguinte maneira (2003: 39):

Interativa/dialógica: o professor e os estudantes exploram idéias, gerando dessa forma novos significados, através da proposta de questões e a partir da consideração de diversos pontos de vista, tanto dos estudantes quanto do professor. 
Não-interativa/dialógica: o professor considera vários pontos de vista, mas esses se restringem apenas ao seu discurso; o professor trabalha e explora as várias perspectivas que surgem desses pontos de vista.

Interativa/de autoridade: o professor objetiva alcançar um ponto de vista específico através de uma seqüência de apresentação de questões que são respondidas pelos alunos.

Não-interativa/de autoridade: o professor apresenta somente um ponto de vista específico.

\section{Padrões de discurso}

Os turnos de fala das aulas ministradas podem ser avaliados como pertencentes ao padrão I-R-A ou ao padrão I-R-F-R-F..., onde (idem, p.41):

I: Iniciação normalmente se dá através de uma pergunta do professor.

R: Resposta do estudante.

A: Avaliação o professor avalia se a resposta está de acordo ou não com o esperado.

F: Feedback do professor, para que o estudante elabore mais a sua fala.

\section{Metodologia}

O estudo envolveu inicialmente um grupo de quinze licenciandos cumprindo e estágio curricular de docência. Numa primeira etapa sondamos, através do questionário, o teor de compatibilidade das concepções de natureza da ciência desses licenciandos com a tendência epistemológica construtivista. Após esse procedimento, selecionamos um licenciando que, de acordo com os resultados do questionário, apresentou ter uma maior tendência construtivista e associamos a essa tendência, por hipótese, uma concepção pedagógica de ciência com maior compatibilidade com as diretrizes dos PCNs. Por fim, a partir da transcrição do registro em vídeo de uma aula ministrada pelo licenciando durante o estágio curricular, analisamos o discurso segundo a estrutura analítica proposta por Mortimer e Scott (2003), com a finalidade de verificar e caracterizar uma prática docente discursiva em conformidade com algumas recomendações dos PCNs. 


\section{O questionário aplicado}

O questionário consta de 5 questões abertas e está apresentado no ANEXO I. Na contagem de pontos, atribuímos 1 ponto positivo às respostas que sugerem uma concepção de Física construtivista e 1 ponto negativo às respostas que sugerem uma concepção de Física nãoconstrutivista. Para respostas indiferentes não atribuímos o valor zero. A seguir seguem as respostas às perguntas e as respectivas atribuições de pontos:

1) Lei é promotora do fenômeno: -1 / Indiferente: 0 / Lei é conseqüência do fenômeno: +1

2) Definitivas: -1 / Indiferente: 0 / Provisórias: +1

3) Unicamente ao gênio de Einstein: -1 / Indiferente: 0 / Contexto histórico: +1

4) Realidade: -1 / Indiferente: 0 / Representação da realidade

5) Sim: -1 / Indiferente: 0 / Não: +1

Assim, na contagem total dos pontos no questionário, um resultado positivo indica uma tendência a uma concepção construtivista. Um resultado negativo representa uma concepção com tendência não-construtivista. Resultados nulos foram considerados não representativos de nenhuma das duas concepções.

\section{Resultados do questionário}

O gráfico apresentado na Figura 1 ilustra os resultados obtidos da aplicação do questionário.

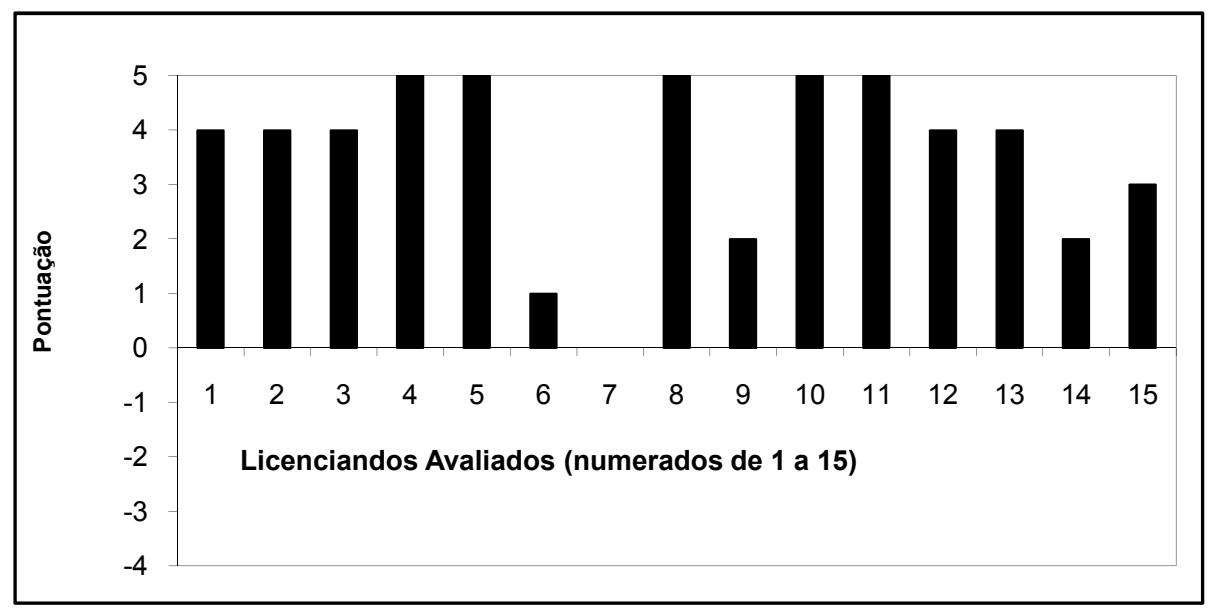

Figura 1: Gráfico da pontuação obtida no questionário por licenciando

Obs: A média aritmética da pontuação obtida foi 3,3 
A partir da Figura 1, podemos perceber que a maior parte dos licenciandos sondados (14 deles) possui em algum grau uma concepção de natureza da ciência construtivista, pois todos os resultados do questionário foram positivos, com exceção do resultado do licenciando 7, cuja pontuação foi nula. Logo, de acordo com nossa hipótese, os licenciandos com pontuação positiva devem possuir também em algum grau uma concepção pedagógica de ciência em acordo com os PCNs. Nenhum licenciando apresentou pontuação negativa; portanto, não houve indícios, a partir desse questionário, de uma tendência por parte dos licenciandos pesquisados em ter uma concepção pedagógica de ciência em desacordo com os PCNs. Apesar de esperarmos evitar resultados tendenciosos com nossa sondagem indireta, mesmo assim não obtivemos na pesquisa representantes com pontuação negativa, devido possivelmente às discussões e bibliografias trabalhadas em torno de temas subjacentes nas disciplinas Prática de Ensino I e II.

Selecionamos um licenciando cuja pontuação positiva foi máxima (5 pontos) e aplicamos o método de análise, descrito anteriormente, em uma de suas aulas regidas durante o estágio curricular de docência.

\section{Aplicação da estrutura analítica à transcrição da aula gravada em vídeo}

A aula transcrita a partir do vídeo foi regida a uma turma do 1 o ano do Ensino Médio de um colégio técnico público. A idade predominante dos alunos era de 15 anos. A duração total do episódio de ensino é de aproximadamente 30 minutos. Os alunos haviam visto recentemente energia potencial e força elástica da mola, como usar um dinamômetro e força e equilíbrio. 0 licenciando pretendia prepará-los para as leis de Newton; para tanto, o objetivo da aula era diferenciar os conceitos de massa e de peso. A seguir, ilustramos as análises a partir de trechos da transcrição que consideramos significativos e sobre os quais tecemos os respectivos comentários e análises. Nosso critério de apresentação das análises dos trechos selecionados se pautou na facilidade de reconhecimento nesses trechos de características representativas da aula como um todo.

O seguinte trecho extraído da transcrição exemplifica como o esquema fechado I-R-F-R-FR-A está presente como elemento mediador da interatividade (a transcrição completa consta no ANEXO II).

Legenda:

$\mathrm{L}$ - licenciando; $\mathrm{A}$ - um aluno qualquer (omitimos os nomes),

$\mathrm{AF}$ - vários alunos falando 
(A numeração se refere aos turnos de fala)

1. L: Alguém sabe me dizer qual a diferença entre peso e massa? (I)

2. A: Peso é em Newtons e massa é em Kilograma (R)

L: (licenciando anota no quadro negro) (F)

3. A: Peso depende do lugar que estou... (R)

4. L: Peso muda dependendo do lugar que estou, e a massa? (F)

5. A: Não, a massa não... (R)

6. L: É o que a gente acabou de ver aqui... (mostrando o desenho do dinamômetro do assunto anteriormente discutido) (A)

Estabelecendo esse padrão de discurso, o licenciando, a partir de contribuições discursivas dos alunos, orienta a discussão e introduz novos elementos conceituais. Em algumas intervenções, o licenciando simplesmente repete as palavras dos estudantes, sendo que essa repetição encoraja os alunos a interagir. Apesar da interação, não há maiores desenvolvimentos dos pontos de vista dos alunos. O licenciando, ao invés de pedir maior elaboração desses pontos de vista, utiliza-os como elos de uma cadeia que leva a discussão para os pontos de vista da ciência. Nesse processo, muitas vezes o licenciando reelabora a fala de um aluno e a devolve para a turma, conforme pode ser verificado no trecho de transcrição a seguir.

11. L: Esta força [peso] depende do que?

12. A: Da massa e da gravidade, peso igual massa vezes aceleração

13. L: Então peso depende da aceleração da gravidade, então depende de onde eu estou...

Quanto à abordagem comunicativa dominante da aula analisada, ela pode ser classificada como interativa - de autoridade, já que, apesar da interatividade com os alunos, o professor não desenvolve ou solicita um desenvolvimento das idéias dos alunos. Na verdade, as contribuições dos alunos entram num jogo de "erro e acerto" com relação ao ponto de vista da ciência. Nesse jogo, os pontos de vista em desacordo são geralmente reelaborados pelo licenciado de modo que se tornem um elo numa cadeia discursiva que visa claramente atingir um objetivo específico: a diferenciação entre massa e peso segundo o ponto de vista científico. Para tanto, o licenciando utiliza em algumas passagens o padrão de discurso encadeado I-R-F-R-F..., o qual encoraja a interatividade com os alunos, sem, no entanto, fornecer respostas diretamente; essas, por sua vez, são elaboradas pelos próprios alunos através do jogo de "erro e acerto". O licenciando, por sua vez, valida ou não as respostas e forja, assim, um certo direcionamento ao foco de seu 
objetivo. Esse direcionamento é geralmente obtido através uma avaliação no final de um encadeamento fechado (por exemplo, encadeamento fechado I-R-F-R-A).

Percebemos que o licenciando explora na sua aula muitos conceitos na categoria de "prérequisitos", tais como aceleração, densidade, átomos, quantidade de matéria. Na nossa avaliação, ele pretende, com a articulação desses conceitos, criar condições propícias à sua meta de desenvolver em seus alunos a capacidade de distinguir massa de peso. Assim, podemos dizer que os chamados "pré-requisitos" são de um caráter essencial no desenrolar desse episódio de ensino no sentido de que o seu compartilhamento servirá de alicerce para construção do conhecimento. De fato, os pré-requisitos nesse episódio de ensino são o centro da avaliação do licenciando que, sempre ao se encontrar em situação que contraria o seu objetivo de aula, se utiliza deles para retornar o diálogo novamente aos rumos que conduzem ao cumprimento do objetivo pretendido.

Entendemos os pré-requisitos como conceitos necessários para o acompanhamento de um novo tópico ou conteúdo; os pré-conceitos, por sua vez, seriam os conceitos dos alunos a respeito de determinadas entidades físicas, que podem tanto coincidir com os pré-requisitos (caso esses conceitos tenham sido abordados e trabalhados anteriormente pelo professor) ou não (caso da não abordagem prévia desses conceitos ou da sua não apropriação por parte dos alunos). $O$ trecho a seguir extraído da aula filmada exemplifica nossas proposições quanto ao uso dos pré-requisitos pelo licenciando (grifos nossos):

44. L: (Riscando no quadro negro um "X" na anotação "massa = quantidade de matéria") Então, o que vocês acham que é massa?

45. Alan: É um trem chato que a gente não sabe o que é...

46. A2: Força é massa vezes a aceleração...

47. A3: Massa é densidade vezes o volume...

48. L: (Desenhando esquemas...) Se aplicar uma força em um objeto com massa " $M$ " e aplicar a mesma força em um outro objeto com massa menor, a aceleração vai ser a mesma?

49. Alan: Não...

50. L: Então, qual vai ser mais difícil de empurrar?

51. Alan: A que tiver maior inércia?

52. AF: Ooooh!!!

53. L: O Alan disse que aquele que tiver maior inércia vai ser mais difícil de empurrar. Então, o que é que vai acontecer?

54. Alan: A aceleração da massa maior vai ser menor... 
A análise da transcrição desse trecho nos leva a inferir que aceleração, força e a própria relatividade das massas (apesar da ainda indefinição de massa) são pré-requisitos necessários aos alunos para acompanhar o raciocínio engendrado pelo licenciando.

Analisando todo o episódio de aula, verificamos que, quanto aos propósitos, o licenciando desenvolve três dos vários propósitos possíveis:

Tabela 4: Os propósitos do licenciando e

os meios pelos quais ele os focaliza

\begin{tabular}{|c|c|}
\hline Propósito do licenciando & Como o licenciando focaliza o propósito \\
\hline Abertura do problema. & $\begin{array}{l}\text { Pergunta direta: } \\
\text { 1. L: Alguém sabe a diferença entre peso e massa?" }\end{array}$ \\
\hline Introduzir e desenvolver os conceitos científicos. & $\begin{array}{l}\text { Disponibilizando os significados científicos no plano } \\
\text { social da sala de aula através do uso dos pré-requisitos } \\
\text { (densidade, aceleração, força). } \\
\text { 13. L: Então peso depende da aceleração da gravidade, } \\
\text { então depende de onde eu estou... }\end{array}$ \\
\hline $\begin{array}{l}\text { Manutenção do desenvolvimento da construção de conceitos } \\
\text { científicos. }\end{array}$ & $\begin{array}{l}\begin{array}{l}\text { Providenciando comentários acerca dos conceitos científicos } \\
\text { ainda não desenvolvidos e ajudando os alunos a seguir o seu } \\
\text { desenvolvimento. }\end{array} \\
\text { 40. L: [se olharmos na tabela periódica] Então em } 1 \mathrm{~kg} \\
\text { de ouro, o número de átomos que vai ter é menor que } \\
\text { em } 1 \mathrm{~kg} \text { de ferro... O que isto significa? } \\
\text { 41. A: Que é diferente... } \\
\text { 42. L: Significa que a quantidade de matéria em } 1 \mathrm{~kg} \text { de } \\
\text { ouro e em } 1 \mathrm{~kg} \text { de ferro é diferente! Mas a massa não é } \\
\text { a mesma? }\end{array}$ \\
\hline
\end{tabular}

\section{Resultado}

Os propósitos do licenciando revelam a intenção de gerar uma construção do conhecimento por parte dos alunos orientada por pré-requisitos (como aceleração, relatividade de massas, força, etc). Essa construção do conhecimento pelos alunos é alcançada por meio de uma abordagem comunicativa predominantemente de autoridade/interativa, que por sua vez é obtida e mantida por meio de um encadeamento do padrão de discurso I-R-F-R-F... Algumas avaliações são feitas por parte do licenciando com o objetivo de promover uma (re)orientação das interações, o que leva a alguns padrões fechados I-R-A ou I-R-F-R-A.

Assim, a estrutura da aula como um todo explora os pré-requisitos. Através da interatividade e articulação entre esses pré-requisitos, o licenciando consegue atingir a meta de levar um dos alunos a diferenciar massa de peso Para essa diferenciação, os pré-requisitos chaves 
são a aceleração e a força - elementos que servem de alicerce na construção dos conceitos massa e peso e, por conseqüência, na sua diferenciação.

Sendo a diferenciação entre massa e peso fruto da assimilação desses conceitos, observase que essa assimilação aparece, ao final da aula, na fala de um aluno (ver o final da transcrição que consta no ANEXO II).. Portanto, é uma conclusão do próprio contexto discursivo didático engendrado pelo licenciando, demonstrando, dessa maneira, o êxito do processo em gerar e discutir novos conceitos científicos.

Assim, o processo desenvolvido no episódio de ensino constituiu-se de formulações e questionamentos iniciais, dos quais se deu prosseguimento a procedimentos que culminaram numa conclusão que foi expressa em termos e convenções de uma sócio-linguagem científica.

Este processo e suas articulações em torno de variáveis físicas a fim de se chegar a novos conceitos (massa, por exemplo) remete a uma concepção pedagógica de ciência em acordo com os PCNs, pois o licenciando orienta discursivamente a aprendizagem dos alunos como uma [re]construção de conhecimentos a partir dos seus conceitos iniciais, que poderão ver-se modificados - como ocorre com os próprios cientistas, - ao longo da pesquisa (GIL-PÉREZ, 2001).

Ou seja, tendo como referência as analises apresentadas e as proposições anteriores, avaliamos que a prática discursiva licenciando e os seus propósitos são compatíveis com as orientações pedagógicas dos PCNs que discutimos anteriormente, o que também é sugerido pela alta pontuação positiva obtida pelo licenciando no questionário aplicado.

\section{Considerações finais}

Um procedimento metodológico de relevo, mas que não foi realizado neste trabalho, seria a realização de uma entrevista semi-estruturada com o licenciando cuja prática foi analisada, tendo como uma das ferramentas de entrevista amostras de trechos de vídeo selecionados. Tal procedimento é uma maneira de gerar uma discussão em torno do enfoque didático utilizado, pois uma atividade que se mostra muito eficaz para que o próprio professor tome consciência de seu comportamento docente espontâneo é a gravação de suas aulas em vídeo e a posterior análise e discussão das mesmas. Durante essa discussão, o professor expõe e utiliza suas concepções espontâneas de uma maneira funcional, ligada ao tratamento dos problemas que o vídeo permitiu evidenciar. E ainda, também de uma maneira funcional, essas concepções podem ser questionadas, como resultado do trabalho de aprofundamento que a discussão gera (CARVALHO, 1989).

É importante salientar que outras variáveis em jogo, além da concepção pedagógica de ciência, podem também influenciar a prática docente, tais como currículos pré-elaborados pela 
escola, constituição e perfil do alunado, motivação pessoal do professor, a possibilidade de utilização de experiências em laboratório, tempo disponível para abordagem dos conteúdos curriculares, motivação pessoal do professor e liberdade institucional para se trabalhar o conteúdo conforme os propósitos do professor, dentre outros. Entretanto, as concepções pedagógicas de ciência nos serviu como um primeiro eixo indicador para a seleção de um licenciando cuja prática discursiva docente seria analisada. Se esta, por sua vez, após as análises, mostrasse-se em contradição com as diretrizes dos PCNs, seria descartada e realizaríamos novamente o procedimento de selecionar outro licenciando de acordo com a maior pontuação no questionário, e assim sucessivamente, até conseguirmos ter acesso a uma prática docente em acordo com os PCNs. Portanto, fica claro para esta pesquisa o caráter orientador, mas não absoluto, das concepções pedagógicas de ciência sugeridas pelo questionário utilizado.

A utilização da estrutura analítica possibilitou o levantamento de diversos aspectos que deram visibilidade às práticas discursivas didáticas do licenciando que, por meio delas, pode estimular uma construção do conhecimento por parte dos seus alunos e, consequentemente, aproximou o perfil da sua prática àquele inscrito nas diretrizes de formação cidadã dos PCNs. Ou seja, especificamente nesse estudo, verificamos a compatibilidade entre a concepção pedagógica de ciência sondada e a prática docente, estando ambas em consonância com as orientações dos PCNs.

Mortimer \& Scott (2003), a partir da perspectiva sociocultural de construção de conhecimentos, sugerem e recomendam que toda sequência de ensino deve passar por variações no discurso produzido em sala de aula. Tais variações seriam responsáveis pelo estabelecimento "ritmos discursivos", os quais, por sua vez, podem entrar ou não em conformidade com as orientações construtivistas dos PCNs. O professor tem um papel fundamental no estabelecimento de tais ritmos, uma vez que ele carrega o status de interlocutor privilegiado em sala de aula, sendo portanto o principal responsável pelo gerenciamento das variações discursivas.

Entretanto, o gerenciamento pelo professor das variações discursivas deve ser didaticamente informado. Os resultados deste trabalho apontam para a necessidade e possibilidade de estudos que busquem ampliar a caracterização de práticas docentes discursivas que sejam consistentes com as recomendações dos PCNs. Com a ampliação desse conhecimento os professores, licenciandos e formadores de professores de física teriam um quadro de referência para orientar didaticamente a sua prática discursiva e planejamento docente, tanto em situações de estágios curriculares quanto na prática docente em serviço.

Uma perspectiva interessante de estudo seria aquela que buscasse caracterizar as diferentes situações discursivas (p.e. narrativas, descritivas, explicativas, argumentativas, etc) no contexto de sala de aula de modo a integrá-las em um modelo que explicite as suas dinâmicas, as 
quais, pela sua natureza esquemática e integrada, poderiam favorecer tomadas de consciência dos professores e licenciandos sobre a sua própria prática docente discursiva e as dos demais. Tal compreensão por parte dos educadores é fundamental se admitirmos que uma reflexão consistente sobre a própria prática deve partir de um conhecimento profundo das suas características. Conforme aponta Perrenoud (2002), no contexto de formação dos professores, pode-se esperar que uma prática reflexiva possibilite as capacidades de inovação, a qual passa a ser entendida como a transformação da própria prática, o que não pode acontecer sem uma análise e compreensão do que é feito e dos motivos para manter ou mudar .

\section{Referências}

ANDRÉ, M. E. D. A. (org.). Formação de professores no Brasil (1990-1998). Brasília: MEC/ Inep/Comped, 2002.

BAKHTIN, M.M. Estética da Criação Verbal. 3a ed. São Paulo: Martins Fontes, 2000.

BRONCKART, J. P. Atividade de linguagem, textos e discursos: por um interacionismo sóciodiscursivo. São Paulo: EDUC, 1999.

CANDELA, A. Prácticas discursivas en el aula y calidad educativa. Revista Mexicana de Investigación Educativa, 4 (8), 273-298, 1999

CARVALHO, A. M. P. Física: proposta para um ensino construtivista. São Paulo: EPU, 1989.

DELIZOICOV, D. ANGOTTI, J. A. PERNAMBUCO, M. M. Ensino de Ciências: fundamentos e métodos. São Paulo: Cortez, 2002.

FRIGOTTO, G.; CIAVATTA, M. Educação básica no Brasil na década de 1990: subordinação ativa e consentida à lógica do mercado. Educação \& Sociedade, V. 24 n. 82, p. 93-130, 2003.

GIL-PÉREZ, D. Formação de professores de ciências: tendências e inovações. 5. ed. - São Paulo: Cortez, 2001.

LEDERMAN, N. G. Teachers' Understanding of the Nature of Science and Classroom Practice: Factors That Facilitate or Impede the Relationship. Journal of Research in Science Teaching, 36, 8, 331-359, 1999.

LOPES, A. C. Políticas curriculares: continuidade ou mudança de rumos? Revista Brasileira de Educação, Rio de Janeiro: ANPEd; Campinas: Autores Associados, n. 26, p.109-118, 2004.

MEC-SEMTEC. Parâmetros Curriculares Nacionais do Ensino Médio (PCNEM). Brasilia: 2002. 
MELLADO, V. Preservice teacher's classroom practice and their conceptions of the nature of science. Science \& Education, 6, p. 331-354, 1997.

MORTIMER, E. F. SCOTT, P. Meaning making in secondary science classrooms. Philadelphia: Open University, 2003.

MUNFORD, D.; LOPES; M. G.; TAVARES, F. P.; VIEIRA, R. D. Práticas discursivas e o ensinoaprendizagem do professor de ciências: tecendo relações entre argumentação e objetivos pedagógicos na formação inicial. Atas do V ENPEC, Bauru, SP, p. 01-12 (CD-ROM), 2005.

OLIVEIRA, E. M. O. Uso das Tecnologias de Informação e Comunicação na Atuação do Professor Gestor do Conhecimento. Dissertação de Mestrado: UFF, 2005

PERRENOUD, P. A Prática Reflexiva no Ofício de Professor. Porto Alegre: Artmed Editora, 2002.

RIBEIRO, V. M.; RIBEIRO, V. M; GUSMÃO, J. B. Indicadores de qualidade para a mobilização da escola. Cadernos de Pesquisa, v. 35, n. 124, p. 227-251, 2005

VIEIRA, R. D. Situações Argumentativas na Abordagem da Natureza da Ciência na Formação Inicial de Professores de Física. Dissertação de Mestrado: Faculdade de Educação, UFMG, 2007.

VIEIRA, R. D.; NASCIMENTO, S. S. A argumentação no discurso de um professor e seus estudantes sobre um tópico de mecânica newtoniana. Caderno Brasileiro de Ensino de Física, 24 (2), p. 174193, 2007.

VYGOTSKY, L. S. Mind in Society: the Development of Higher Psychological Processes. Cambridge, MA: Harvard University Press, 1978. 


\section{ANEXO I - 0 questionário aplicado}

1) Para você, a lei da gravitação de Newton foi uma lei descoberta - no sentido de que já existia como promotora dos fenômenos gravitacionais - ou foi uma lei inventada - no sentido de que foi formulada a partir do fenômeno e sendo por isso uma conseqüência dele, estando, por isso, sujeita a modificações na medida em que fossem observadas novas características no fenômeno que não pudessem ser explicadas pela referida lei?

2) O surgimento da Relatividade devido a certas incompatibilidades teóricas entre a Mecânica Clássica de Newton e o Eletromagnetismo de Maxwell é, na sua opinião, indício de que essas três teorias são definitivas ou provisórias?

3) Na sua opinião, o surgimento da Teoria da Relatividade Restrita surgiu devido unicamente ao gênio de Einstein ou o contexto histórico e científico da época já apontava para o seu surgimento, independentemente da figura de Einstein?

4) Você entende as teorias físicas como uma representação da realidade ou como a própria realidade?

5) Há teorias físicas que prevêem certos fenômenos; entretanto, na medida em que a previsão falha, a História da Física nos mostra que essas teorias foram reformuladas. Você acha que chegará o dia em que esse processo de reciclagem de teorias chegará ao fim com o surgimento da suposta Teoria do Tudo? 


\section{ANEXO II - Transcrição de aula analisada.}

Tema: Peso vs. Massa. Duração aproximada: 30 minutos.

$\mathrm{L}$ - licenciando; A - aluno qualquer (omitimos os nomes); AF - vários alunos falando ao mesmo tempo.

A numeração se refere aos turnos de fala.

As expressões entre parênteses são comentários do transcritor que buscam esclarecer e contextualizar determinados trechos discursivos.

1. L: Alguém sabe me dizer qual a diferença entre peso e massa?

2. A: Peso é em newtons e massa é em kilograma (professor anota no quadro negro)

3. A: Peso depende do lugar que estou...

4. L: Peso muda dependendo do lugar que estou, e a massa?

5. A: Não, a massa não...

6. L: É o que a gente acabou de ver aqui... (mostrando o desenho do dinamômetro do assunto anteriormente discutido)

7. L: Se formos para a Lua, a gente vai pesar menos?

8. $\mathrm{A}: \ldots$

9. L: Medida de peso é em newtons, então o que é peso?

10. A: Força...

11. L: Esta força depende do que?

12. A: Da massa e da gravidade, peso igual massa vezes aceleração

13. L: Então peso depende da aceleração da gravidade, então depende de onde eu estou...

14. A:...

15. L: Se eu estiver na Lua, qual que vai ser a aceleração da gravidade?

16. A: Aceleração da gravidade é menor, g é mais ou menos $1,6 \mathrm{~m} / \mathrm{s}^{2} \ldots$ da Terra é de $10 \mathrm{~m} / \mathrm{s}^{2}$

17. L: (anotando no quadro negro) na Lua é $1,6 \mathrm{~m} / \mathrm{s}^{2} \ldots$

18. A: Isto aí é um g? 
19. L: (apaga e escreve o g mais legível...) Se estou aqui na Terra e "peso" cem kilos, quanto vou "pesar" na Lua?

20. A: É só dividir por seis. É um bom jeito de emagrecer sem nenhum esforço... risos...

21. L: Se a pessoa for para a Lua, ela emagreceu? Não emagreceu, né?

22. A: É que a gravidade ficou menor, mas a massa ficou a mesma. Aí o peso diminuiu... é $\mathrm{P}=\mathrm{mg}$

23. L: Então o que é massa?

24. AF: É quantidade de matéria num corpo...

25. L: (anotando no Q.N.) é quantidade de matéria. É isso mesmo?

26. A: É isso mesmo...

27. L: (perguntando para o resto da turma) Vocês acham que é isso mesmo?

28. (alguns alunos falam...)

29. L: Vou fazer a pergunta aqui: $1 \mathrm{~kg}$ de ouro e $1 \mathrm{~kg}$ de ferro tem a mesma quantidade de matéria?

30. A: Não, a densidade do ouro é maior...

31. A: E a quantidade de matéria depende das moléculas

32. L: Vocês têm na química o mol, não tem?

33. A:...

34. L: Vocês já viram o mol na química?

35. A: Alguns já viram, é $6.10^{23} \ldots$

36. L: Alguém sabe o peso atômico do ouro?

37. A:...

38. L: (anotando os valores no Q.N.) Olhando na tabela periódica, você vai ver que o ouro tem peso atômico bem maior que o do ferro. Então, $1 \mathrm{~kg}$ de ouro tem a mesma quantidade de matéria que $1 \mathrm{~kg}$ de ferro?

39. A: Se eu pesar vai dar igual. Mas a quantidade de átomos que tem de ouro é menor que a de ferro.

40. L: Então em $1 \mathrm{~kg}$ de ouro, o número de átomos que vai ter é menor que em $1 \mathrm{~kg}$ de ferro... O que isto significa? 
41. A: Que é diferente...

42. L: Significa que a quantidade de matéria em $1 \mathrm{~kg}$ de ouro e em $1 \mathrm{~kg}$ de ferro é diferente!... Mas a massa não é a mesma?

43. A: É a mesma, mas a quantidade de matéria é diferente...

44. L: (Riscando no Q.N. um X na anotação massa = quantidade de matéria) Então, o que vocês acham que é massa?

45. A: É um trem chato que a gente não sabe o que é...

46. A: Força é massa vezes a aceleração...

47. A: Massa é densidade vezes o volume...

48. L: (Desenhando esquemas...) Se aplicar uma força em um objeto com massa " $M$ " e aplicar a mesma força em um outro objeto com massa menor, a aceleração vai ser a mesma?

49. A: Não...

50. L: Então, qual vai ser mais difícil de empurrar?

51. A: A que tiver maior inércia!?

52. Alunos: Ooooooh!!!!

53. L: O A disse que aquele que tiver maior inércia vai ser mais difícil de empurrar. Então, o que é que vai acontecer?

54. A: A aceleração da massa maior vai ser menor...

55. L: Todo mundo entendeu?

56. A: Explica de novo...

57. L: Se eu aplicar a mesma força em um objeto de massa "M" e em outro com massa "m" menor, qual vai ter maior aceleração?

58. A: O objeto com m menor...

59. L: (apontando para o desenho e desenhando os vetores aceleração) Esse aqui, né? Vou colocar "A" maiúsculo aqui e "a" minúsculo aqui. Isto significa o que?

60. A: Inércia!?

61. L: Como o A concluiu, massa é quantidade de inércia... 
Rodrigo Drumond Vieira - UFMG, DMTE (Departamento de Métodos e Técnicas de Ensino) rodrigo_vdrumond@yahoo.com.br

Silvania Sousa do Nascimento - UFMG, DMTE (Departamento de Métodos e Técnicas de Ensino) silvania.nascimento@gmail.com

Carlos Eduardo Porto Villani - UFMG, DMTE (Departamento de Métodos e Técnicas de Ensino) carlosvillani@yahoo.com.br 